\title{
A Detailed Study on The Real Estate Sector Employees in İstanbul Via Questionnaire Survey
}

\author{
Özge EREN ${ }^{1}$, Çiğdem ÖZARI ${ }^{2}$ \\ ${ }^{1}$ Istanbul Aydin University, Turkey. \\ ${ }^{2 I}$ stanbul Aydin University, Turkey.
}

\begin{abstract}
This study aims to examine job satisfaction at the real estate sector according to various variables and the research depends onSurvey Questionnaire Model. The research group, randomly selected,126employees working in real estate sector in Istanbul.Firstly, some demographic questions were asked and then Minnesota Satisfaction is carried out to participants.The analysis was carried out through Descriptive and Inferential Statistics. The main purpose of this study was to illustrate the applicability of Multiple Correspondence Analysis (MCA) in detecting and representing underlying structures on the datasetsand also by using Principal Component Analysis we obtained significant factors about job satisfaction questions
\end{abstract}

Keywords: Job Satisfaction, Multiple Correspondence Analysis (MCA), Real Estate, Principal Component Analysis

\section{Introduction}

Turkey has the $17^{\text {th }}$ largest economy in the world with a Gross Domestic Product (GDP) of $\$ 799.54$ billion and also is a member of the OECD, G20 countries and one of the largest upper-middle income partners of the World Bank Group. In addition, Turkey became a candidate for full European Union (EU) membership at the Helsinki summit in 1999 (World Bank Countries Overview, 2015).

Since 1980s, the real estate sector is one of the main important sector that advances Turkey's economy. The real estate sector in Turkey represents $19.5 \%$ of the total GDP and offers a great potential for national and international investors. In addition, we can say that this sector is a flourishing industry in Turkey. Within a very short span of time, real estate has become one of the most lucrative businesses of the country and over the last decade this sector has become extremely competitive. In Turkey, 37.9 percent of the mortgage loans are utilized in Istanbul, 59 percent in the largest three cities and 85 percent in the first 20 cities where the loans are mostly utilized. (GYODER, 2016) Istanbul, which is not the capital, is the one of the greatest cities of Europe with its history, location of connecting two continents and population of 14 million. Also, real estate sector has the highest share in İstanbul. Considering these reasons, we want to analyze job satisfaction in this sector. There are various definitions of job satisfaction. Hackman and Oldham (1980) refer to the persistent feelings a person has toward his/her work. Job satisfaction has been also defined as a positive emotional state resulting from the pleasure a worker derives from the job (Locke, 1976; Spector, 1997).In addition we can say that job satisfaction is one of the important requirements for employees' motivation. If employees are satisfied on their job then they will be encouraged to render their better services, they will be more committed to the job and to the organization. George and Jones (1996:70) define job satisfaction as "the collection of feelings andbeliefs that people have about their currentjobs". According to Johns (1992), jobsatisfaction is a collection of attitudes thatworkers have about their jobs. In another perspective, jobsatisfaction may be defined in terms of theway people react to their work environment.Gannon (1979:186), for example, views jobsatisfaction as the "difference between theamount of some valued outcome a personreceives and the amount of that outcome". Francis and Melbourne (1980) attempt to summarize the various definitions of job satisfaction as a result of the individual's perception of what is needed and what is received from different facets of the worksituation. Accordingto theTINY pulse's "2016 Best Industry Rankings" (Reltor, 2016)survey which was asked to more than 60.000 employees from 13 different industries, real estate sector was ranked in the second place, after the consumer products and services.

Job satisfaction related studies in real estate sector focus on different areas. Kabir's study (2015)measures job satisfaction of employees in real estate sector via questionnaire analysis in Bangladesh. According to the results of this study, the real estate business in Bangladesh needs to follow some recommendations or suggestions for the benefits of individual employee.Jiang Jing's studyis about factors affecting job satisfaction in foreign invested real estate companies in China. The results from this study may confirm the hypothesis that employees in foreign invested real estate companies have a lower job satisfaction compared with people who work in local companies. Aravind and Vasanthakumara assess the degree of employee satisfaction and questionnaires were administered to the employees in the real estate company.Various factors such as employee's experience, communication skills and etc... On employee 
satisfaction was conducted by using linear regression analysis.Coninck explored the impact of real estate salespeople's career stages on attitudes toward their jobs and performance. The sample consisted of 241 fulltime real estate salespeople in Missouri. The results of this study showed that real estate salespeople in the exploration stage had lower job performance than real estate salespeople in the other career stages. Another study of interactive service between staff and customers in the Australian real estate industry was carried outby Gountasin 2009. Self-efficiency and job satisfaction also have positive and significant relationships with customer orientation. The study also indicates significant differences in the employee's responses according to age, experience and job position.

\section{Research Methodology}

The aim of this study was to measure the degree of job satisfaction whichwas conducted through a survey for the real estate companies of Istanbul. The study involves the evaluation of the degree of job satisfaction of the employees using three factors which are mainly designated as self-improvement, time efficiency and work environment satisfaction. In this study the data was obtained by the direct administration of questionnaires to the employees. Questions were framed in a way that the answers reflect the ideas and thoughts of the employees with regard to their job satisfaction level. The population unit was finite and was composed of 126 employees working for the real estatecompany in İstanbul.In this study, firstly descriptive statistics (e.g. frequencies and percentages) was used to describe the data in summary form and Table 2.1 illustrates the frequencies of variables of analysis which are gender, franchise status, education status and level of their experience in the real-estate sector.

Table 2.1: Frequency Distribution of Demographic Variables

\begin{tabular}{|l|l|l|l|}
\hline Variable & Categories & Frequencies & $\%$ \\
\hline Gender & Woman & 49 & 39 \\
\hline & Men & 77 & 61 \\
\hline Franchise Status & 1 (Yes) & 34 & 27 \\
\hline & 2 (No) & 91 & 72 \\
\hline Ages & & & \\
\hline & $18-30$ & 64 & 50 \\
\hline & $31-43$ & 40 & 31 \\
\hline & $43-55$ & 14 & 11 \\
\hline Education Status & Primary School & 8 & 6 \\
\hline & Secondary School & 23 & 7 \\
\hline & High School & 65 & 18 \\
\hline & University & 27 & 51 \\
\hline & Post Graduate & 2 & 21 \\
\hline Experience (Years) & $0-3$ & 31 & 2 \\
\hline & $4-6$ & 40 & 24 \\
\hline & $7-10$ & 32 & 31 \\
\hline & $11-14$ & 8 & 25 \\
\hline & $15-19$ & 8 & 6 \\
\hline & $20+$ & 6 & 6 \\
\hline & & & 5 \\
\hline
\end{tabular}

The employee from the real-estate sector are asked to fill out a questionnaire. Using this questionnaire, our main aim is to measure the self-improvement, time efficiency and work-environment satisfaction parts or factors of job satisfaction. In 1967, Weiss et all develops the short version of Minnesota satisfaction questionnaire.Our questionnaire (survey) is based on five point Likert type scale with 15 items and Table 2.2 illustrates the scale.

Table 2.2: Likert Scale

\begin{tabular}{|l|l|}
\hline Corresponding Remark & Score \\
\hline Strongly Disagree & 1 \\
\hline Disagree & 2 \\
\hline Not Applicable & 3 \\
\hline Agree & 4 \\
\hline Strongly Agree & 5 \\
\hline
\end{tabular}

Since Cronbach's a (alpha) is a coefficient of reliability, we use it in this study to asses internal consistency of Likert type questions. The cronbach's alpha value for each factor is shown in Table 2.3

Table 2.3: Representation of Cronbach alpha value for each factor

\begin{tabular}{|l|l|}
\hline Factor & Cronbach's Alpha \\
\hline Self-improvement & 0.853 \\
\hline Time Efficiency & 0.690 \\
\hline Work Environment Satisfaction & 0.889 \\
\hline
\end{tabular}


If the value of Cronbach's Alpha is greater than 0.7, it means that the factors are consistent and in addition, this study revealed 0.796 as Cronbach's alpha value for the entire survey questionnaires.

Hypothesis tests on contingency tables are based on a statistic called Chi-square. This test evaluates when two variables are independent of each other. In order to carry out the contingency test, the primary data was classified into different demographic factors such as gender, age, experience and education level. In this study, the hypothesis was tested at $\% 5$ level of significance. Null hypothesis is denoted by $\mathrm{H}_{\mathrm{o}}$ and alternative hypothesis is denoted by $\mathrm{H}_{1}$ as usual and defined as follows.

Ho:There is no difference between two variables

$\mathbf{H}_{1}$ : There is a difference between two variables

To verify the distribution of observed data with assumed theoretical distribution, Chi-square test is applied to test the goodness of fit. Table 2.4, 2.5 and 2.6 illustrate construction of self-improvement, time efficiency and work environment satisfaction; respectively.

Table 2.4: Construction of Self-Improvement

\begin{tabular}{|l|l|l|l|}
\hline Demographic Factors & Chi-Square & P-Value & Result \\
\hline Gender & 2090 & 0.000 & Suggestive Evidence against $\mathrm{H}_{0}$ \\
\hline Age & 2115 & 0.000 & Suggestive Evidence against $\mathrm{H}_{0}$ \\
\hline Experience & 2343 & 0.000 & Suggestive Evidence against $\mathrm{H}_{0}$ \\
\hline Education level & 2010 & 0.000 & Suggestive Evidence against $\mathrm{H}_{0}$ \\
\hline
\end{tabular}

Table 2.5: Construction of Time Efficiency

\begin{tabular}{|l|l|l|l|}
\hline Demographic Factors & Chi-Square & P-Value & Result \\
\hline Gender & 61.99 & 0.005 & Suggestive Evidence against $\mathrm{H}_{0}$ \\
\hline Age & 57.123 & 0.014 & Suggestive Evidence against $\mathrm{H}_{0}$ \\
\hline Experience & 73.869 & 0.01 & Suggestive Evidence against $\mathrm{H}_{0}$ \\
\hline Education Level & 56.457 & 0.016 & Suggestive Evidence against $\mathrm{H}_{0}$ \\
\hline
\end{tabular}

Table 2.6:Construction of Work Environment Satisfaction

\begin{tabular}{|l|l|l|l|}
\hline Demographic Factors & Chi-Square & P-Value & Result \\
\hline Gender & 55.958 & 0.038 & Suggestive Evidence against $\mathrm{H}_{0}$ \\
\hline Age & 67.772 & 0.03 & Suggestive Evidence against $\mathrm{H}_{0}$ \\
\hline Experience & 67.654 & 0.07 & Suggestive Evidence against $\mathrm{H}_{0}$ \\
\hline Education level & 56.035 & 0.038 & Suggestive Evidence against $\mathrm{H}_{0}$ \\
\hline
\end{tabular}

The calculated Pearson Chi-Square values are also seen at the Table 2.4, 2.5, 2.6. The associated PValue (Asymptotic significance) are less than 0.05 (for the all of the factors) indicating that there is evidence against the null hypotheses and therefore they are rejected.

We can say that Multiple Correspondence Analysis (MCA) is one of the visual technique that nominal (multiple nominal) data can be easily mapped.MCA is an extension of correspondence analysis (CA) which allows one to analyze the pattern of relationships of several categorical dependent variables (Abdi \& Valentin). MCA is used to analyze a set of observations described by a set of nominal variables. For instance, gender is a nominal variable with two levels 1 and 0 . When the number of nominal variables to analyze is large and some have high cardinality, MCA could run out of memory, depending on how it is implemented.

The history of multiple correspondence analysis can be traced back to Hirschfeld (1935). Fisher (1940) used same ideas in the framework of discriminant analysis and one can say that he is one of the founding fathers of this technique. The efforts of improving the analysis continued with Jean-Paul Benzécri and in the following years it has been used as an important ordering technique (Greenacre and Vrba, 1984). This is a visual analysis which measures and explains the relationship between the variables on graphs (Greenacre, 2007). The weakness of the analysis is that the non-existence of hypothesis assumptions(Heijden and Leew,1985). On the other hand, this weakness creates an opportunity of easy application of the analysis. Also one of the greatest advantages of the analysis is it can be run for rows and columns separately(Lebart and others 1984).

The first step in a correspondence analysis is to examine the profiles (the set of relative frequencies). Profile values are calculated separately for rows and columns.

Row Mass $=$ Row Sums $\left(n_{i+}\right) /$ Grand Total $(n)$

Column Mass $=$ Column Sums $\left(n_{+\mathrm{j}}\right) /$ Grand Total $(n)$

Correspondence matrix is defined as the original matrix $\mathrm{N}$ divided by the grand total $n$.

The matrix of row/column profiles can be defined as the rows/columns of the correspondence matrix $P$ divided by their respective row/column masses, which can be written as: Matrix of Row Profile: $D_{\mathrm{r}}^{-1} P$ and Matrix of Column Profiles $=D_{\mathrm{c}}^{-1} P$

where $D_{\mathrm{r}}$ is the diagonal matrix of row masses and $\mathrm{D}_{\mathrm{c}}$ is the diagonal matrix of the column masses.

The correspondence analysis problem is to find a low-dimensional approximation to the original data matrix that represents both the row and column profiles: $R=D_{\mathrm{r}}{ }^{-1} P$ and $C=D_{\mathrm{c}}^{-1} P$. 
$\mathrm{T}$ is the matrix which measures each observation value of the distance between row and column matrices as calculated in Equation 1.

$T=\left[P-r c^{T}\right]=\left[n_{i j}-P_{i .} P_{. j}\right](1)$

where $\quad i=1 \ldots \ldots . r$

$\mathrm{T}$ matrix is obtained by multiplying with the square root of columns and rowmatrix asin equation 2 .

$D_{r}^{\frac{1}{2}} T D_{c}^{\frac{1}{2}}=U \Lambda V^{T}$

$D_{r}$ and $D_{c}$ are the diagonal matrices that represents the weights of rows and columns, respectively. While determining coordinates of graphs in CA, singular value decomposition is used. $F$ and $G$ represents the coordinates of rows and columns, respectively and they are calculated by the help of equation 3 and equation 4 .

$F=D_{r}^{-\frac{1}{2}} U \Lambda^{\frac{1}{2}}$

$G=D_{c}^{-\frac{1}{2}} U \Lambda^{\frac{1}{2}}=G(4)$

How to settle the demographic elements in the two-dimensional plane is shown in Figure 2.1. If the points are close to each other, it was defined as similar points. In other words, closeness referred to similarity. There are so important implications in Figure 2.1. We can easily say that men's monthly sales and leasing is lower than women's(Gender 2 and monthly sale-rent 1 and monthly sale-rent 2 attends in so similar locations on the table). According to the figure, persons who graduates the university are youngest. From this perspective educational levels are increasing depending on the year. The best number of sale and rent were achieved from the by high school graduates (monthly sale rent-5 and Education level 3).

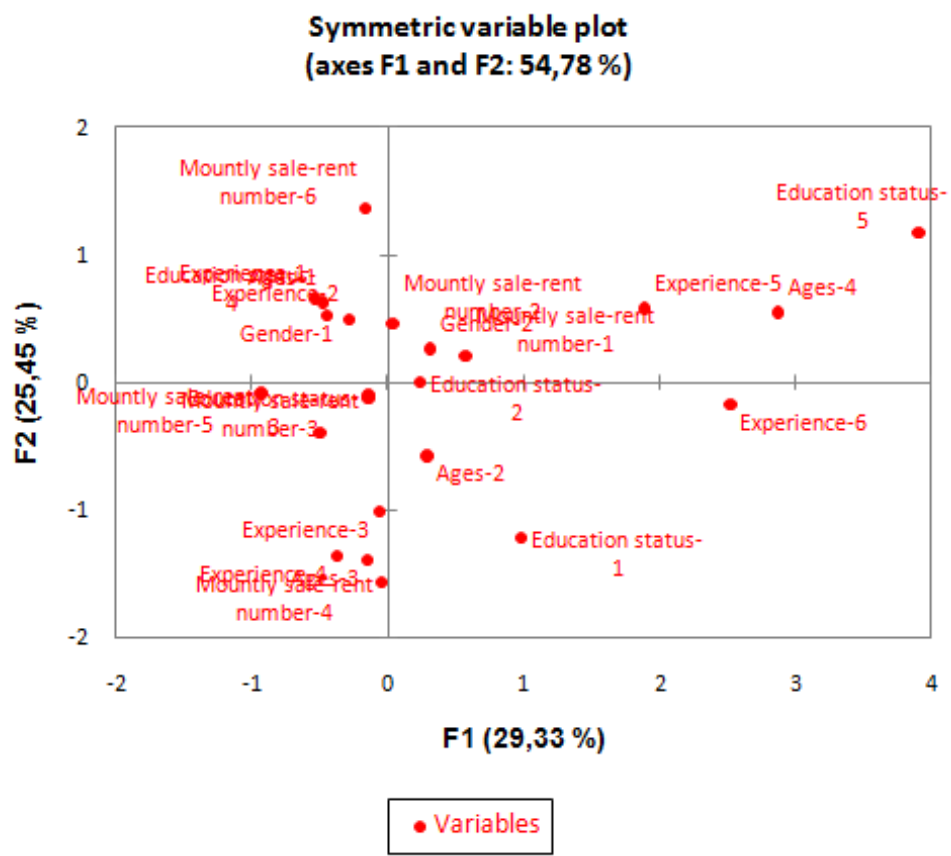

Figure 2.1: MCA Variable Plot

In this study to asses job satisfaction level with the 13 question (Table above), it was used Principal Component Analysis due to reducing the questions meaningful factors.In principal components analysis (PCA) and factor analysis (FA) it aims to extract from a set of $p$ variables a reduced set of $m$ components or factors that accounts for most of the variance in the $p$ variables. In other words, It is a technique that allows you to reduce values from several variables into a single variable.

Table 2.7: Questions about job satisfaction

\begin{tabular}{ccccc}
\hline Variable & Minimum & Maximum & Mean & Std. deviation \\
\hline 1. Question & 2 & 5 & 4.456 & 0.767 \\
2. Question & 2 & 5 & 4.404 & 0.772 \\
3. Question & 1 & 5 & 4.221 & 0.928 \\
4. Question & 2 & 5 & 4.424 & 0.765 \\
\hline
\end{tabular}




\begin{tabular}{lllll}
\hline & & & & \\
\hline 5. Question & 2 & 5 & 4.344 & 0.834 \\
6. Question & 1 & 5 & 4.001 & 1.047 \\
7. Question & 1 & 5 & 4.168 & 0.918 \\
8. Question & 1 & 5 & 3.929 & 1.189 \\
9. Question & 1 & 5 & 3.935 & 1.008 \\
10. Question & 1 & 5 & 3.841 & 1.103 \\
11. Question & 1 & 5 & 3.083 & 1.556 \\
12. Question & 1 & 5 & 2.88 & 1.522 \\
13. Question & 1 & 5 & 3.047 & 1.592 \\
\hline
\end{tabular}

Table 2.7 illustrates the main statistics such as maximum- minimum value, mean and standard deviation for 13. question that we used in questionnaire to asses job satisfaction level. In this analysis, it was used Principal Component Analysis due to getting meaningful factors. It aims to extract from a set of $p$ variables a reduced set of $m$ components or factors that accounts for most of the variance in the $p$ variables. In other words, it is a technique that allows you to reduce values from several variables into a single variable

Factor $(\mathrm{F})$ is called a construct, latent variable or unmeasured variable. X's are called indicators, manifest variables or measured variables. These underlying factors are inferred from the correlations among the $p$ variables. Each factor is estimated as a weighted sum of the $p$ variables. The $i^{\text {th }}$ factor denoted by $\mathrm{F}_{\mathrm{i}}$ is defined as Equation 5.

$$
F_{i}=W_{i 1} X_{1}+W_{i 2} X_{2}+\ldots+W_{i p} X_{p}(5)
$$

Some authors suggest that PCA should only be done on continuous variables, preferably with normal distributions (Jolliffe, s.65). However, in this analysis we used this technique for categorical type of data. There are some important measurement to use the results in PCA.First one is Barlett's test and another one is Kaiser Meyer Olkin test.Bartlett's test for sphericity can be used to test the hypothesis that the correlation matrix is an identity matrix. (If there is an underlying structure the variables should be correlated). You can reject the null hypothesis if the data are suitable for FA.Bartlett's sphericity test'sresult is meaningful as it's shown Table 2.8

Table 2.8: Barlett Test

\begin{tabular}{ll}
\hline Chi-square (Observed value) & 787.729 \\
Chi-square (Critical value) & 99.617 \\
DF & 78 \\
P-value & $<0.0001$ \\
Alpha & 0.05 \\
\hline
\end{tabular}

Kaiser-Meyer-Olkin (KMO) is a kind of measure sampling adequacy for comparing the magnitudes of the observed correlation coefficients to the magnitude of the partial correlation coefficients (partial correlations should be small if the variables share common factors). Values closer to $1(>.5)$ is suitable for the analysis so our KMO index is 0.796 .

Another important indicator for the PCA is explained variance percentage which tells us how much of the variance in our data is explained by each component and is useful for determining if a component is worth examining. First component always explains the greatest variance; this value must be greater than the others. In our analysis, explained variance percentage is $\% 65$ and significant component number is 3 .

Table 2.9: Component's Variablity

\begin{tabular}{cccc}
\hline & Component 1 & Component 2 & Component 3 \\
\hline Variability (\%) & 29.509 & 19.904 & 15.692 \\
\hline Cumulative (\%) & 29.509 & 49.413 & 65.106 \\
\hline
\end{tabular}

According to Table 2.9 there are three possible factors, which explain $65,106 \%$ of the total variance in the data, which is middle-level good result (only eigenvalues $>1$ ) The first factor has about $29 \%$ variability of the total variance. 
Table 2.10 shows the Component Matrix which express the loading of each variable onto each factor. At this stages it can be shown the table three meaningful factors. First component express that self improvement structure the second one time efficiency and last factor work environment satisfaction structures

Table 2.10:Component Matrix

\begin{tabular}{|c|c|c|c|}
\hline & $\mathbf{D}_{1}$ & $\mathbf{D}_{2}$ & $\mathbf{D}_{3}$ \\
\hline 1.Question & 0.564 & & \\
\hline 2.Question & 0.645 & & \\
\hline 3.Question & 0.581 & & \\
\hline 4.Question & 0.606 & & \\
\hline 5.Question & 0.628 & & \\
\hline 6.Question & 0.329 & & \\
\hline 7.Question & 0.387 & & \\
\hline 8.Question & & & 0.567 \\
\hline 9.Question & & & 0.602 \\
\hline 10.Question & & & 0.457 \\
\hline 11.Question & & 0.745 & \\
\hline 12.Question & & 0.865 & \\
\hline 13.Question & & 0.87 & \\
\hline
\end{tabular}

\section{Conclusion}

The purpose of the study is to identify the overall job satisfaction contribute with demographic factors in İstanbul on real sector employees. In today's world, Job satisfaction is a topic of wide interest for people who work in organizations. There are some studies related with job satisfaction in the world. However, when we examine the literature in detailed for Turkey, We've found a few study about this topic. In order to collect required data for this study, the Minnesota Satisfaction Questionnaire (MSQ) short form was used as a tool. Firstly, descriptive statistics were used to see demographic structures. For another perspective, to analyze the data visually, it has been used MCA. By using this technique, some important facts were obtained. One of them is women are more successful than men and to asses job satisfaction level with the some questions. Findings of the some statistics shows that employee in real-estate sector of İstanbul generally satisfied with their job with different levels (A mean of greater than 3 denoted satisfaction, while a mean less than 3 denoted dissatisfaction). Items on job satisfaction were measured at interval level and analyzed with PCA. It was used because of getting meaningful factors. Using the principal component technique $15 \mathrm{sub}$ factors were reduced to 3 main factors such as: self improvement, time efficiency and last factor work environment satisfaction. This study was accomplished with one city which is İstanbul. In the coming studies, academician can research the same subject on the different city.

\section{References}

[1]. World Bank, "Countries Overview", (Online) http://www.worldbank.org/en/country/turkey/overview (10.08.2016)

[2]. GYODER, "Real Estate Research Report 10", (Online)http://www.gyoder.org.tr/img/mc-content/2 0150122095548_2795report10.pdf (7.08.2016)

[3]. Kabir , Mohammad Jonaed Measuring Employee Job Satisfaction In Real Estate Business: A Study On Some Selected Companies In Bangladesh The International Journal of Sciences Vol 34 No.1 pages 18-30

[4]. Abdi, Herve. (2007). "Encyclopedia of Measurement and Statistics". Neil Salkind (Ed.) Thousand Oaks (CA) :Sage

[5]. Hirschfeld, H.O. (1935) A connection between correlation and contingency. Proceedings of the Cambridge Philosophical Society, Mathematical and Physical Sciences: 31, 520-524.

[6]. IOSR Journal of Business and Management (IOSR-JBM)e-ISSN: 2278-487X, p-ISSN: 2319-7668. Volume 11, Issue 4 (Jul. - Aug. 2013), PP 40-46 Mr. Aravind Krishnan V Dr. S.A. Vasanthakumara

[7]. Managing the Real Estate Salesforce Through Career StagesJim De Coninck Journal of Professional Services Marketing Vol. 10 , Iss. 1,1994

[8]. Sandra Gountas, The Employees' Perspective on Customer Orientation in the Real Estate Industry, School of Management, La Trobe University, Melbourne, Australia

[9]. Benzécri, J.-P. (1973). L'Analyse des Données. Volume II. L'Analyse des Correspondances. Paris, France: Dunod

[10]. Greenacre, M.J. \& Vrba, E.S. (1984) Graphical display and interpretation of antelopecensus data in African wildlife areas, using correspondence analysis. Ecology : 65, 984-997.

[11]. Michael Greenacre, Correspondence Analysis In Practice, 2.Ed., Boca Raton, Chapman \& Hall/CRC Press, 2007, s.1.

[12]. Pter G. van der Heijden, Antonie de Falguerolles, Jan de Leew, "A Combined Approach to Contingency Table Analysis Using Correspondence Analysis and Loglinear Analysis”, Applied Statistics, Vol 38, No:2, 1989

[13]. Van der Heijden, P.G.M, and de Leeuw, J. (1985), "Correspondence Analysis Used Complementary to Loglinear Analysis," Psychometrika, 50, 429 - 447.

[14]. Lebart, L., Morineau, A., and Warwick, K.M. (1984), Multivariate Descriptive Statistical Analysis: Correspondence Analysis and Related Techniques for Large Matrices, New York: John Wiley \& Sons, Inc

[15]. Jolliffe, I.T. (2002). Principal Component Analysis, second edition (Springer). 